\title{
'Per ardua ...' Training tomorrow's surgeons using inter alia lessons from aviation
}

\author{
C R Jackson ${ }^{1} \quad$ K P Gibbin ${ }^{2}$
}

J R Soc Med 2006;99:554-558

It is incumbent on today's surgeons to produce the next generation of well-trained and qualified surgeons. There are many aspects to becoming a surgeon (or becoming a 'better' surgeon). First, there are the intellectual aspects, the learning of anatomy, physiology and the like. Then there are the practical skills, the manual dexterity, and the tissue handling skills. Additional aspects include leadership, good decision-making, judgement and good communication skills. Whilst some of these abilities are innate in a trainee, many must also be taught and all will need to be assessed.

Generations of surgeons have learnt largely as an apprentice. As this model has been effective, why change it? There is a dramatic reduction in operating exposure amongst current trainees as compared with their predecessors, who were trained as Registrar and then Senior Registrar. This has arisen from the Calman review of training in the recent past. Hours of work and length of training will be further shortened by the implementation of both the European Working Time Directive ${ }^{1}$ and the introduction of the 'Modernising Medical Careers' programme. ${ }^{2}$ All surgical specialties are being required to reduce the overall indicative length of training, but with assessment of that training against a background of required competencies.

Additionally, whilst the majority of surgeons are of a high calibre, a few still conform to old stereotypes of poor communicators - or, worse, lack technical skills. Particularly in today's litigious society, neither is acceptable. Training must encompass all aspects of becoming a surgeon and failing trainees must be identified and supported, or even directed to alternative careers.

With these factors in mind it is important to assess how to improve on the current training in order to obviate the effects of the reduction in the time available for it. Authors have often looked to other industries, particularly the aviation industry, for parallels that can be applied. We can also take examples of best practice from other countries.

${ }^{1}$ Specialist Registrar in Paediatric Surgery, Royal Victoria Infirmary, Newcastle upon Tyne NE1 4LP, UK ${ }^{2}$ Consultant Otolaryngologist, Queen's Medical Centre, Nottingham, NG7 2UH, UK

Correspondence to: KP Gibbin

E-mail: Kevin.gibbin@nuh.nhs.uk
This article aims to draw on both arenas to discuss training methods and risk management in surgery.

\section{SELECTION}

In order to optimize training it is imperative to first ensure the best candidates are selected. The Royal Air Force introduced aptitude testing for aircrew selection in 1944 following research with Cambridge University, validation being an ongoing process. The selection process for doctors starts with medical school. Whilst exam results may be used to assess academic ability, a structured interview can be used to predict later job performance. ${ }^{3}$ Previous academic performance is a moderate predictor of undergraduate success, accounting for $23 \%$ of the variance in overall performance, but has only a small effect (6\%) on postgraduate competence. ${ }^{4}$ At Senior House Officer and Specialist Registrar level, the typical format is application form or Curriculum Vitae combined with unstructured references and a short interview. The validity of such methods is often questioned but as yet a good alternative has not been clearly identified. In particular, tests of manual dexterity have not been shown to be of benefit in selecting surgeons, although spatial ability does correlate with surgical skill. ${ }^{5}$

Competency based selection systems have been applied, notably in General Practice in the Trent region: a candidate completes a competency based application form with examples of their best practice; the reference is structured, with scores attributed against the defined competencies; and a whole-day assessment exercise includes simulations, written responses and a technical interview. This combination was designed to provide 'a range of in-depth information about candidates' knowledge, skills and abilities' and improves the validity of selection. ${ }^{6}$

A national selection system would allow prospective trainees to know the detailed requirements for entry into the grade and would standardize applications across deaneries. The Royal College of Surgeons of England (RCSE) and a number of the Surgical Specialty Advisory Committees (SACs) are addressing the issue of selection criteria to be applied nationwide. The RCSE is considering a staged process including practical courses with competitive marking before a final structured interview. National 
criteria could be applied locally or alternatively potential trainees could be selected and ranked nationally and then matched to an appropriate local training scheme. A centralized matching scheme in America (the San Francisco Matching Program) has been shown to be largely successful, with high trainee satisfaction with the process. ${ }^{7}$

\section{DEFINING COMPETENCIES}

Both trainers and trainees need to understand what is required of them throughout training. The competency based approach is already evident in medicine - for example the RITA (Record of In Training Assessment) process - but in many areas it is not fully defined. ${ }^{8}$ Robust higher order competencies must be defined by the relevant subspecialties and encompass the entirety of the doctor's role. Some competencies will be relevant across a multitude of disciplines.

The Royal Air Force defines the following competencies for its trainees, many of which are applicable to surgeons:

- confidence and resilience;

- oral communication;

- problem solving ability;

- team working.

These can be cross-referenced to the competencies delineated by the Royal College of Physicians and Surgeons of Canada in the CanMEDS document. ${ }^{9}$ The CanMEDS 2000 project, a multi-agency review of the training needs of all Canadian doctors, generated generic competencies applicable across all specialties. The seven key areas were:

- medical expert/clinical decision maker;

- communicator;

- collaborator;

- manager;

- health advocate;

- scholar;

- professional.

These competencies are equally applicable to British trainees and are being used within the Intercollegiate Surgical Curriculum Project at The Royal College of Surgeons of England.

\section{TRAINING METHODS}

A practical comparison with aviation is the use of simulators. These are used extensively within aviation, not only in initial pilot training but also for crew transferring to alternative aircraft. The advantages for air safety are evident; pilots can become familiar with equipment but also learn to manage emergencies without putting lives at risk. The surgical field has attempted to follow suit, particularly with the advent of laparoscopic surgery. The vast difference in the level of sophistication between aviation and medicine can be directly related to the resource implications. An A320 aircraft simulator will cost in the region of $£ 12$ million, compared with a few thousand pounds for a basic surgical simulator. Virtual reality simulators can both assess and improve psychomotor skills: ${ }^{10}$ studies show reduced operating time, reduced error rates and improved economy of movement. ${ }^{11,12}$

\section{THE INTERNATIONAL EXPERIENCE}

The United States has largely avoided the issue of reduction in hours of training and its potential effect on standards. Although working hours for trainees have supposedly been reduced to 80 hours per week, surveys show that its trainees continue to work hours far in excess of this and of those expected of the average British trainee. The Accreditation Council for Graduate Medical Education limits scheduled hours to 80 but in specific cases this may be increased by a further $10 \% .^{13}$ In one study, $45 \%$ of residents worked over 100 hours per week; one in four of the residents questioned also regretted choosing a surgical career. ${ }^{14}$ Additionally, recruitment to General Surgery in the United States is becoming more difficult. ${ }^{13}$

Canada successfully negotiated a reduction in residents' hours (although only to around 80 hours per week) without compromising surgical experience. One factor stressed is positive changes in education with improved resources, including skills courses and the use of simulators. ${ }^{15}$

Europe is to some extent also avoiding the effects of the European Working Time Directive (EWTD). For example, in Portugal 'non-compliance is the rule rather than the exception', in Germany 'most hospital doctors' working hours exceed those stipulated' and in Holland 'the 48-hour week does not include on-call work'. ${ }^{16}$ There are significant concerns over the implementation of the EWTD; indeed, the President of the European Surgical Association suggested 'working hours are being restricted in some places to degrees incompatible with the acquisition of sufficient surgical experience and volume. ${ }^{13}$

\section{RISK MANAGEMENT}

The National Patient Safety Agency estimates that 900,000 incidents harming or nearly harming patients occur each year amongst NHS hospital inpatients. ${ }^{17}$ Singh et al. ${ }^{18}$ reviewed their urological practice and found over half of patient episodes had a near miss incident, with clinical error accounting for $23 \%$ of incidents.

Reason ${ }^{19}$ describes two approaches to analysing human error: the person approach blames an individual for a mistake. The 'blame culture' has long been the typical style 
of NHS management. The alternative, the system approach, accepts that humans are fallible and builds defences into any given system to increase its safety. The Swiss Cheese Model of Error demonstrates that when holes in multiple defensive layers are aligned, an accident trajectory is created. An accumulation of small errors inside and outside the operating theatre can be catastrophic. The systems approach has been demonstrated to be a useful model in surgical error analysis in paediatric cardiac surgery and its utilization could enhance patient safety. ${ }^{20}$

Analysis of aviation accidents revealed human factors to be the predominant cause: the CAP681 report ${ }^{21}$ identified the causes of 621 fatal airline accidents over a 16-year period. Crew causes were the primary causal factor in $76 \%$. Subsequent training in human factors has contributed to reduced accident rates in aviation. Medicine can apply many of the techniques used, particularly 'red flags' to mark a deviation from standard practice or encountering unexpected operative findings. ${ }^{22}$ Standard operating procedures in aviation translate into guidelines or formalized protocols in medicine, allowing new and changing teams to work together efficiently and safely. Aviation experts stress the importance of crew resource management, otherwise known as teamwork, in reducing error rates. Communication within teams may be improved by formal handovers, such as the pre- and postoperative briefings used by the Cornwall theatre project, ${ }^{23}$ of which a formal review is awaited.

Both accidents and near misses must be analysed objectively and in detail to identify system failures. ${ }^{18}$ As error reporting rates rise, serious errors decrease, but a recent survey demonstrated significant underreporting of errors, with perhaps as few as $15 \%$ being reported. ${ }^{24}$ It should be remembered that the reporting of adverse events is a requirement of all surgeons under 'Good Surgical Practice', as described by The Royal College of Surgeons of England. ${ }^{25}$ Full reporting of incidents will only be achieved if the system is fully anonymized and does not apportion blame. It is hoped that the new National Reporting and Learning System developed by the National Patient Safety Agency will closely mimic the success of its aviation predecessor, the Confidential Human factors Incident Reporting Programme (CHIRP). CHIRP is run by a nonregulatory body, is financed as a charity, is anonymous and publishes its findings at regular intervals to allow pilots to learn from others' mistakes.

\section{LEARNING CURVES}

In aviation, crew experience has an inverse relationship to accident rates, which are five times as likely in the younger than older age groups (25 accidents per 1000 pilots aged 16-19 years versus 5 accidents per 1000 pilots aged over
60). ${ }^{26}$ Learning curves have long been recognized in surgery, whether referring to a trainee learning an established technique or to an experienced consultant learning a new procedure. However, the Senate of Surgery response to the General Medical Council enquiry into the Bristol Paediatric Cardiac Surgical Unit stated 27 'There should be no learning curve as far as patient safety is concerned.' Hasan et al. ${ }^{28}$ suggest a practical method of minimizing the effect of the learning curve on the patient, in the context of a new procedure for an experienced surgeon. The process starts with attendance at a masterclass, followed by cadaveric dissection, before performing the operation with an expert in the field. Finally, a second consultant should assist the first with the operation, rather than involving a trainee. The Specialist visitor has much to offer.

A study by Bridgewater et al. ${ }^{29}$ of outcomes of cardiac surgery demonstrated a progressive decrease in the observed mortality during the first few years of a new consultant appointment. The suggestion is that the learning curve here relates to the non-technical aspects of surgery, such as case selection and decision making skills. The teaching of such skills should be an integral part of training in surgery.

\section{ROLE MODELS}

There is a need to inculcate professional values, attitudes and behaviours in students and young doctors, and this has traditionally come from role models. ${ }^{30}$ The personal qualities of such individuals include enthusiasm, compassion and integrity in addition to their clinical and teaching skills; responsibility and status can also be perceived as attractive. ${ }^{31-34}$

Role models are known to have a strong influence on career choice; ${ }^{35}$ most people can cite an individual who inspired their choice of career or subspecialty. In a survey of 352 senior American surgeons, role models were the most common reason for choosing a surgical specialty, with $47 \%$ of respondents making their choice at junior residency level. ${ }^{36}$ If students do not encounter surgical specialities in medical school or during the Foundation years, it makes these subjects unlikely career choices. It is imperative that medical schools continue to offer the broadest possible curriculum. It is of concern therefore that a number of medical schools no longer offer clinical experience in Otolaryngology; Mace and Narula highlighted this, demonstrating that six of the 27 medical schools in the UK do not include ENT training. ${ }^{37}$ Additionally, there is some evidence that women are put off surgery as medical students or pre-registration House Officers, without good exposure to this field. ${ }^{38}$ Surgery must continue to attract the best candidates, regardless of gender. 


\section{MENTORING}

The term mentoring arises from The Odyssey: Mentor was Odysseus's friend and nurtured his son Telemachus while Odysseus was away at war. The term has come to mean promoting the development of the whole person to full capacity. A mentor helps to cultivate professional values and behaviours aside from the practical requirements of the job and can offer a sympathetic ear when discussing difficult cases or situations. All trainees - but new consultants in particular - may benefit from such a relationship; indeed, most senior surgeons can cite such an individual who aided in their professional development.

\section{CONCLUSION}

In conclusion we believe that tomorrow's surgeons will be of an equal standard to the current generation, despite the time constraints, but with several caveats. There must be a serious commitment from all parties to prioritize training. The authors agree with the comments made by Talbot ${ }^{39}$ that training 'should include slow incubation, acquiring knowledge formally, stepwise and slowly and facilitated reflection on experience ... . all this takes time' and caution against further reductions in the time made available for training, as opposed to service. This will almost certainly require some sacrificing of service provision within the NHS and there will be significant resource implications. Finally, as hours continue to fall with the implementation of the European Working Time Directive, it becomes increasingly important that surgeons are assessed by competency and not simply by the duration of training.

Note This paper is based on the Presidential address to the Section of Otology of the Royal Society of Medicine on 5 November 2004.

Contributions C R Jackson prepared the manuscript; K P Gibbin gave the original presentation and revised the text.

\section{Competing interests None declared.}

\section{REFERENCES}

1 McDonald R. How protective is the working time directive? BMJ 2004;329:301-2

2 Donaldson L (Chief Medical Officer). Unfinished Business. Proposals for the Reform of the SHO Grade. London: NHS Consultation Paper, August 2002

3 Hughes P. Can we improve on how we select medical students? J R Soc Med 2002;95:18-22

4 Ferguson E, James D, Madely L. Factors associated with success in medical school: systematic review of the literature. BMJ 2002;324:952-7

5 Graham KS, Deary IJ. A role for aptitude testing in surgery? J Roy Coll Surg (Edinb) 1991;36:70-4

6 Patterson F, Ferguson E, Norfolk T, Lane P. A new selection system to recruit general practice registrars: preliminary findings from a validation study. BMJ 2005;330:711-4
7 Lansford CD, Fisher SR, Ossoff RH, Chole RA. Otolaryngology-head and neck surgery residents match: applicant survey. Arch Otolaryngol Head Neck Surg 2004;130:1017-23

8 Leung W. Competency based medical training: review. BMJ 2002;325:693-6

9 CanMEDS 2000 project. Skills for the new millennium: report of the societal needs working group. Canada: The Royal College of Physicians and Surgeons of Canada, September 1996

10 Taffinder N, Sutton C, Fishwick R. Validation of virtual reality to teach and assess psychomotor in laparoscopic surgery: results from randomised controlled studies using the MIST VR laparoscopic simulator. Stud Health Technol Inform 1998;50:124-30

11 Grantcharov T, Kristian V, Bendix J, et al. Randomized clinical trial of virtual reality simulation for laparoscopic skills training. $\mathrm{Br} J$ Surg 2004;91:146-50

12 Seymour N, Gallagher A, Roman S, et al. Virtual reality training improves operating room performance: results of a randomised blinded study. Ann Surg 2002;236:458-63

13 Harder F. 'I would like to be a Surgeon, but . . . ' Ann Surg 2002;236:699-702

14 Niederee MJ, Knudtson JL, Byrnes MC, et al. A survey of residents and faculty regarding work hour limitations in surgical training programs. Arch Surg 2003;138:663-9

15 Romanchuk K. The effect of limiting residents' work hours on their surgical training: a Canadian perspective. Acad Med 2004;79:384-5

16 Mayor S, Burgermeister J, Kosner $\mathrm{K}$, et al. Over the limit. BMJ 2004;329:310-1

17 www.npsa.org.uk

18 Singh R, Saleemi A, Walsh K, et al. Near misses in bladder safety - an airline safety approach to urology. Ann R Coll Surg Engl 2003;85: $378-81$

19 Reason J. Human error: models and management. BMJ 2000;320: $768-70$

20 Catchpole KR, Giddings AE, De Leval MR, et al. Identification of systems failures in successful paediatric cardiac surgery. Ergonomics 2006; in press

21 CAP 681. Global fatal accident review. London: UK Civil Aviation Authority, May 2002

22 Coxon J, Pattison S, Parks J, et al. Reducing human error in urology: lessons from aviation. BJU Int 2003;91:1-3

23 Cornwall Theatre Team Resources Management Project. Have a safe landing. Hospital Doctor 2004;16

24 White C. Doctors mistrust systems for reporting medical mistakes. BMJ 2004;329:12

25 The Royal College of Surgeons of England. Good Surgical Practice. London: RCS, September 2002

26 Taylor L. Chapter 2: Human Factors. In: Air Travel. How safe is it? Oxford: BSP Professional Books, 1998

27 Senate of Surgery. Response to the General Medical Council determination on the Bristol case. London: Senate of Surgery, 1998

28 Hasan A, Pozzi M, Hamilton J. New surgical procedures: Can we minimise the learning curve? BMJ 2000;320:171-3

29 Bridgewater B, Grayson A, Au J, et al. Improving mortality of coronary surgery over first four years of independent practice: retrospective examination of prospectively collected data from 15 surgeons. BMJ 2004;329:421-4

30 Swick HM, Szenas P, Danoff D, Whitcomb ME. Teaching professionalism in undergraduate medical education. JAMA 1999;282:830-2

31 Wright S. Examining what residents look for in their role models. Acad Med 1996;71:290-2

32 Wright SM, Kern DE, Kolodner K, et al. Attributes of excellent attending-physician role models. NEJM 1998;339:1986-93 
33 Paice E, Heard S, Moss F. How important are role models in making good doctors? BMJ 2002;325:707-10

34 Elzubeir M, Rizk D. Identifying characteristics that students, interns and residents look for in their role models. Med Educ 2001;35:272-7

35 Wright S, Wong A, Newill C. The impact of role models on medical students. J Gen Intern Med 1997;12:53-6

36 Ko CY, Whang EE, Karamanoukian R, et al. What is the best method of Surgical Training? A report of America's leading surgeons. Arch Surg $1998 ; 133: 900-5$
37 Mace AD, Narula AA. Survey of current undergraduate otolaryngology training in the United Kingdom. J Laryngol Otol 2004;118: $217-20$

38 Williams C, Cantillon P. A surgical career? The views of junior women doctors. Med Educ 2000;34:602-7

39 Talbot M. Good wine may need to mature: a critique of accelerated higher specialist training. Evidence from cognitive neuroscience. Med Educ 2004;38:399-408 